\title{
Um relato de experiência sobre a aplicação de duas estratégias de ensino para tratar da ética no serviço público brasileiro no município de São Francisco do Conde
}

\author{
Adelmaria lone dos Santos ${ }^{1}$ \\ Jacqueline Silva da Silva²
}

\section{Resumo}

Apresenta a experiência realizada em sala de aula com a aplicação de duas estratégias de ensino: aula expositiva dialogada e Phillips 66 no processo de ensino e de aprendizado sobre ética no serviço público. A aplicação ocorreu com servidores que ocupam a função de assistentes de classe, vinculados a uma Secretaria municipal de um município baiano. Os resultados revelaram que as duas estratégias corroboraram para tornar as aulas mais dinâmicas, desconstruindo o tradicional monólogo na relação professor - aluno. O estudo conclui que a estratégia da aula expositiva traz desafios para os docentes, sendo recomendada em disciplinas de 40 ou 60 horas. Já a Phillips 66 é adequada para resgatar pontos de um tema debatido como também revelar possíveis lacunas no processo de aprendizagem.

Palavras-chave: Relato de Experiência; Estratégia de Ensino; Ética no Serviço Público.

An experience report on the application of two teaching strategies to address ethics in the Brazilian public service in the municipality of São Francisco do Conde

\section{Abstract}

It presents the classroom experience with the application of two teaching strategies: dialogued lecture and Phillips 66 in the teaching and learning process on ethics in the public service. The application occurred with servers that occupy the function of Class Assistants, linked to a municipal Secretariat of a city of Bahia. The results revealed that both strategies collaborated to make the classes dynamic, deconstructing the traditional monologue in the teacher - student relationship. The study concludes that the lecture strategy presents challenges for teachers, being recommended in subjects of 40 or 60 hours. Phillips 66 is well suited to redeem points from a debated topic as well as revealing possible gaps in the learning process.

Keywords: Experience Report; Teaching Strategy; Ethics in the Public Service.

\section{Introdução}

Trata-se de um relato de experiência que foi elaborado a partir do curso de formação sobre ética no serviço público, ministrado para servidores públicos municipais, lotados na Secretaria de Educação do município de São Francisco do Conde, no Estado da Bahia. O

\footnotetext{
${ }^{1}$ Universidade da Integração Internacional da Lusofonia Afro-Brasileira (UNILAB), São Francisco do Conde, Bahia. Email: adelmariaione@unilab.edu.br.

2Universidade do Vale do Taquari (UNIVATES), Lajeado, Rio Grande do Sul. E-mail: jacqueh@univates.br.
} 
referido curso está inserido no programa de capacitação para servidores, ofertado pela Escola de Governo, vinculada à Secretaria de Gestão Administrativa do município. O curso apresenta carga horária de 24 horas e ocorreu no mês de março de 2018 aos servidores que trabalham como assistente de classe do ensino fundamental. Este teve por objetivo discutir acerca dos conceitos de ética na atividade profissional, considerando a dimensão ética como pressuposto fundamental para ofertar, ao cidadão, um serviço público garantidor do bem-estar de direito social. A partir dos objetivos propostos, os conteúdos ministrados abordaram, de modo geral, aspectos conceituais da ética, sob uma ótica filosófica e normativa. Para a abordagem dessas temáticas, utilizamos as seguintes estratégias de ensino: aula expositiva dialogada e Phillips 66. Para atingirmos aos objetivos deste relato de experiência realizamos uma primeira discussão sobre as estratégias de ensino encontradas na literatura, lastrando a discussão com base em alguns dos principais autores do tema. No segundo momento, descrevemos a metodologia e os resultados da experiência na aplicação das duas estratégias de ensino escolhidas e, por último, finalizamos o artigo com as principais considerações.

\section{As estratégias de ensino no fazer docente}

É importante ter em mente que o momento histórico atual conhecido como pósmodernidade tem como principal característica a crítica à modernidade; às ideias tradicionais deixaram de ser referências e as verdades passaram a ser questionadas. Na pós-modernidade, o ambiente é dinâmico, complexo e cheio de incertezas. Nela, surgem novas propostas como a valorização da subjetividade, do multiculturalismo e da pluralidade (BAUMAN, 2002).

Nas instituições de ensino, a mudança principal ocorre na relação professor/aluno, na qual este último passou a ser reconhecido como sujeito no processo de ensino e aprendizagem porque, de acordo com Anastasiou e Alves (2004),eles chegam às salas de aula, trazendo toda uma bagagem de conhecimentos oriundas de suas caminhadas pelo mundo da vida, não cabendo mais ao professor desconsiderá-las por completo, ensinando-os como se fazia no modelo tradicional de ensino com foco apenas na transmissão de conhecimento, pois, conforme os autores citados acima, o aprendizado deixou de ser um processo de memorização de informação para transformar-se num processo de construção de saberes, tendo como ponto 
de partida a realidade do aprendiz.

Apesar de realidades diversas, muitos dos aprendizes que frequentam as salas de aulas contemporâneas estão imersos numa sociedade da informação ou numa sociedade do conhecimento, na qual as tecnologias eletrônicas e informacionais parecem possuir grandes significados em suas vidas (MORAN, 2012). Assim, esse cenário traz enormes desafios para todos os atores que estão inseridos no campo educacional. Aos coordenadores pedagógicos, por exemplo, cabe o desafio de pensarem em técnicas pedagógicas que contemplem os novos dispositivos eletrônicos; aos professores, por sua vez, é preciso incorporar novas estratégias de ensino que levem em consideração as potencialidades das tecnologias eletrônicas. Enfim, esse cenário, como nos propõe Anastasiou e Alves (2004), deve ser pensado desde o projeto político e pedagógico das escolas até o processo de ensinagem.

Nesse sentido, diante de um cenário marcado por constantes transformações tecnológicas, os professores precisam pensar constantemente em como tornar os conteúdos trabalhados em sala de aula mais claros, objetivos e atrativos para os seus alunos, e é justamente nesse contexto que a temática sobre as estratégias de ensino parece ganhar grande relevância na prática docente. Entretanto, como bem enfatizam Anastasiou e Alves (2004), a prática docente e suas estratégias de ensino não podem estar desarticuladas do projeto político e pedagógico da escola, da organização curricular, dos objetivos interdisciplinares da instituição (módulos, ações, eixos, problemas, projetos etc.) para não correrem o risco de fracassar, justamente por não levarem em consideração o conjunto de elementos que fortalecem o trabalho docente.

Quando nos deparamos com o termo "estratégia" logo pensamos em caminhos, passos, percursos que poderão ser pensados e efetivados para atingirmos determinados objetivos previamente estabelecidos. No âmbito comercial, a palavra estratégia está relacionada, de modo geral, aos caminhos traçados pelas empresas e demais atores comerciais para aumentarem a lucratividade dos negócios. Já no âmbito militar, a palavra estratégia pode ser pensada como meios utilizados por uma nação, no sentido mais amplo do termo, para vencer guerras e impor sua cultura e seus hábitos às nações vencidas. E no ensino, o que significa estratégia?

A estratégia de ensino, de acordo com Anastasiou e Alves (2004), pode ser entendida 
como a arte de aplicar ou explorar os meios e condições favoráveis e disponíveis, visando a efetivação da ensinagem. Para os autores referenciados, é importante atrelar a escolha da estratégia ao objetivo que se pretende alcançar com o processo de ensinagem. Uma espécie de contrato deve ser firmando entre os sujeitos envolvidos.

Segundo Anastasiou, através das estratégias aplicamos ou exploramos meios, modos, jeitos, formas de evidenciar o pensamento, portanto, respeitando às condições favoráveis para se executar ou fazer algo. Esses meios ou formas comportam determinadas dinâmicas, devendo considerar o movimento e as forças, e o organismo em atividade. Por isso, o conhecimento do aluno pelo professor e seu crescente autoconhecimento é essencial para a escolha e a efetivação da estratégia, com seu modo de ser, agir, estar e sua dinâmica pessoal (ANASTASIOU; ALVES, 2004, p. 63).

Na citação acima é possível perceber, que o estabelecimento de uma estratégia de ensino precisa levar em conta a realidade nas quais os alunos estejam inseridos. Assim, uma estratégia de ensino pensada para um grupo de crianças pode não ter o mesmo efeito, por exemplo, quando aplicada para um grupo de adolescentes ou mesmo para um grupo de adultos, assim como uma estratégia de ensino pensada para um grupo de alunos da zona rural pode não ter a mesma recepção em um grupo de alunos da zona urbana, isto é, antes de se pensar em uma estratégia de ensino, o professor precisa conhecer muito bem o perfil dos seus alunos.

Para além do conhecimento do perfil dos alunos, os professores também precisam ser coerentes consigo mesmos, já que além de terem que conhecer as potencialidades e as limitações de cada uma das estratégias para assim escolherem aquela que melhor se adeque à realidade dos seus alunos, eles também devem possuir um conhecimento acumulado sobre determinada temática para optarem pela melhor estratégia, que lhes permita dar maior brilho ao seu saber acumulado. É nesse sentido, que Anastasiou e Alves (2004), na citação anterior, chamam à atenção para a necessidade do autoconhecimento do professor.

Observa-se que a literatura registra uma série de estratégias que podem ser utilizadas pelos professores para tornar o processo de ensino e aprendizagem mais eficaz para os seus alunos. A aula expositiva dialogada, por exemplo, é uma estratégia na qual o professor expõe o conteúdo, promovendo uma participação mais ativa dos seus alunos. A estratégia do estudo 
dirigido consiste numa proposta de promover o estudo sob a orientação de um professor para sanar dificuldades específicas. Já a estratégia do estudo de texto consiste na exploração das principais ideias de um autor a partir do estudo crítico de um texto. Por sua vez, a estratégia de ensino e pesquisa busca instigar o aluno para a prática da pesquisa, da curiosidade, provocando-o para que ele não seja apenas um reprodutor de conhecimentos, mas que gere novas interpretações sobre a realidade.

As estratégias supracitadas são apenas um pequeno recorte das variadas possibilidades de ensinagem que um professor pode utilizar para abordar o conteúdo didático em sala de aula. Anastasiou e Alves (2004), por exemplo, trazem um universo de 20 (vinte) estratégias de ensino que podem subsidiar os professores em seu fazer didático, sendo que a escolha delas depende muito das habilidades que o docente quer desenvolver em seus alunos. No quadro a seguir, apresentamos uma síntese conceitual de cada uma das estratégias de ensino encontradas na literatura.

Quadro 1 - Definição das Estratégias de Ensino

\begin{tabular}{|c|c|}
\hline Estratégia Descrição & Descrição \\
\hline $\begin{array}{l}\text { Aula expositiva } \\
\text { Dialogada }\end{array}$ & $\begin{array}{l}\text { Consiste numa exposição do conteúdo com a participação ativa dos estudantes, } \\
\text { cujo conhecimento prévio deve ser considerado e pode ser tomado como ponto } \\
\text { de partida. }\end{array}$ \\
\hline Estudo de texto & $\begin{array}{l}\text { Consiste na exploração de ideias de um autor a partir do estudo crítico de um } \\
\text { texto e/ou a busca de informações e exploração de ideias dos autores estudados. }\end{array}$ \\
\hline Portfólio & $\begin{array}{l}\text { Consiste na identificação e a construção de registro, análise, seleção e reflexão } \\
\text { das produções mais significativas ou identificação dos maiores } \\
\text { desafios/dificuldades em relação ao objeto de estudo, assim como das formas } \\
\text { encontradas para superação. }\end{array}$ \\
\hline $\begin{array}{l}\text { Tempestade } \\
\text { cerebral }\end{array}$ & $\begin{array}{l}\text { Consiste numa possibilidade de estimular a geração de novas ideias de forma } \\
\text { espontânea e natural, deixando funcionar a imaginação. }\end{array}$ \\
\hline Mapa conceitual & $\begin{array}{l}\text { Consiste na construção de um diagrama que indica a relação de conceitos em uma } \\
\text { perspectiva bidimensional, procurando mostrar as relações hierárquicas entre os } \\
\text { conceitos pertinentes à estrutura do conteúdo. }\end{array}$ \\
\hline Estudo dirigido & $\begin{array}{l}\text { Consiste no ato de estudar sob a orientação e diretividade do professor, visando } \\
\text { sanar dificuldades específicas. É preciso ter claro: o que é a sessão, para que e } \\
\text { como é preparada. }\end{array}$ \\
\hline $\begin{array}{l}\text { Lista de discussão } \\
\text { por meios } \\
\text { informatizados }\end{array}$ & $\begin{array}{l}\text { Consiste na oportunidade de um grupo de pessoas poder debater, à distância, um } \\
\text { tema sobre o qual sejam especialistas ou tenham realizado um estudo prévio, ou } \\
\text { queiram aprofundá-lo por meio eletrônico. }\end{array}$ \\
\hline
\end{tabular}




\begin{tabular}{|c|c|}
\hline $\begin{array}{l}\text { Solução de } \\
\text { problemas }\end{array}$ & $\begin{array}{l}\text { Consiste no enfrentamento de uma situação nova, exigindo pensamento } \\
\text { reflexivo, crítico e criativo a partir dos dados expressos na descrição do problema; } \\
\text { demanda a aplicação de princípios, leis que podem ou não ser expressas em } \\
\text { fórmulas matemáticas. }\end{array}$ \\
\hline Phillips 66 & $\begin{array}{l}\text { Consiste numa atividade grupal em que são feitas uma análise e uma discuss } \\
\text { sobre temas / problemas do contexto dos estudantes. }\end{array}$ \\
\hline $\begin{array}{l}\text { Grupo de } \\
\text { verbalização e de } \\
\text { observação } \\
\text { (GV/GO) }\end{array}$ & $\begin{array}{l}\text { Consiste na análise de tema/problemas sob a coordenação do professor, a } \\
\text { divide os estudantes em dois grupos: um de verbalização (GV) e outro } \\
\text { observação (GO). }\end{array}$ \\
\hline Dramatização & Consiste numa apresentação teatral, a partir de um foco, problema, tema etc. \\
\hline Seminário & $\begin{array}{l}\text { Consiste num espaço em que as ideias devem germinar ou ser semead } \\
\text { Portanto, espaço, no qual um grupo discuta ou debata temas ou problemas q } \\
\text { são colocados em discussão. }\end{array}$ \\
\hline Estudo de caso & $\begin{array}{l}\text { Consiste na análise minuciosa e objetiva de uma situação real que necessita s } \\
\text { investigada e é desafiadora para os envolvidos. }\end{array}$ \\
\hline Júri simulado & $\begin{array}{l}\text { Consiste na simulação de um júri em que, a partir de um problema, sã } \\
\text { apresentados argumentos de defesa e de acusação. }\end{array}$ \\
\hline Simpósio & $\begin{array}{l}\text { Consiste na reunião de palestras e preleções breves apresentadas por vári } \\
\text { pessoas (duas a cinco) sobre um assunto ou sobre diversos aspectos de u } \\
\text { assunto. Possibilita o desenvolvimento de habilidades sociais, de investigaçã } \\
\text { amplia experiências sobre um conteúdo específico, desenvolve habilidades } \\
\text { estabelecer relações. }\end{array}$ \\
\hline Painel & $\begin{array}{l}\text { Consiste na discussão informal de um grupo de estudantes, indicados pe } \\
\text { professor (que já estudaram a matéria em análise, interessados ou afetados pe } \\
\text { problema em questão), em que apresentam pontos de vista antagônicos } \\
\text { presença de outros. }\end{array}$ \\
\hline Fórum & $\begin{array}{l}\text { Consiste num espaço do tipo "reunião", no qual todos os membros do grupo tê } \\
\text { a oportunidade de participar do debate de um tema ou problema determinado. }\end{array}$ \\
\hline $\begin{array}{l}\text { Oficina } \\
\text { (laboratório ou } \\
\text { worshop). }\end{array}$ & $\begin{array}{l}\text { Consiste na reunião de um pequeno número de pessoas com interesses comur } \\
\text { a fim de estudar e trabalhar para o conhecimento ou aprofundamento de u } \\
\text { tema, sob orientação de um especialista. }\end{array}$ \\
\hline Estudo do meio & $\begin{array}{l}\text { Consiste num estudo direto do contexto natural e social, no qual o estudante } \\
\text { insere, visando a uma determinada problemática de forma interdisciplinar. }\end{array}$ \\
\hline $\begin{array}{l}\text { Ensino com } \\
\text { pesquisa }\end{array}$ & $\begin{array}{l}\text { Consiste na utilização dos princípios do ensino associados aos da pesquis } \\
\text { Concepção de conhecimento e ciência em que a dúvida e a crítica seja } \\
\text { elementos fundamentais; assumir o estudo como situação construtiva } \\
\text { significativa, com concentração e autonomia crescente; fazer a passagem } \\
\text { simples reprodução para um equilíbrio entre reprodução e análise. }\end{array}$ \\
\hline
\end{tabular}
Fonte: Anastasiou e Alves (2004)

A partir da análise do quadro acima, o leitor pode imaginar as possibilidades e as limitações de cada uma das estratégias de ensino, pensando em como aplicá-las no seu cotidiano escolar. O quadro evidencia, ainda, as interações entre as estratégias que poderão ser adaptadas, modificadas ou mesmo combinadas pelo docente, conforme julgar conveniente ou necessário. 
A estratégia escolhida para ministrar o curso sobre ética no serviço público com servidores municipais da cidade de São Francisco do Conde, no recôncavo da Bahia, recaiu sobre a aula expositiva dialogada e Phillips 66.

A aula expositiva dialogada surge como uma alternativa ao modelo tradicional da educação bancária, denunciada por Paulo Freire, na qual o professor deposita o conhecimento no aluno que o recebe passivamente. Dessa forma, a aula expositiva dialogada

[...] é uma estratégia que vem sendo proposta para superar a tradicional palestra docente. Há grandes diferenças entre elas, sendo que a principal é a participação do estudante que terão as suas observações consideradas, analisadas e respeitadas, independentemente da procedência e da pertinência das mesmas. O clima de cordialidade, parceria, respeito e troca são essenciais (ANASTASIOU; ALVES, 2009, p.86).

Como revela a citação acima, o diálogo entre professor e aluno torna-se fundamental no processo de ensino e aprendizagem dentro da sala de aula. Nessa concepção, o professor deixa de ser apenas um transmissor de conhecimento, aquele que possui a maior autoridade epistêmica dentro da sala, para transformar-se num sujeito libertador, questionador, indagador que permita construir conhecimentos a partir da realidade dos seus alunos e, nesse processo, os alunos passam a ser os principais protagonistas na construção de novos conhecimentos.

Já a estratégia de ensino denominada Phillips 66 tem por objetivo provocar a participação de todos os alunos na discussão de um determinado tema trabalho pelo professor em sala de aula. É uma estratégia recomendada para ser aplicada em turmas numerosas, uma vez que permite o agrupamento de estudantes em número de 6 (seis) que, num intervalo de 6 (seis) minutos e, por isso 66, deverão apresentar uma síntese sobre determinado tema trabalhado em sala de aula.

A referida estratégia é um excelente instrumento na consecução do levantamento de opiniões e apreciação de problemas de natureza social, política, educacional e cultural, sendo utilizada tanto para os momentos de mobilização, quanto para a elaboração de sínteses. A Phillips 66 possibilita um ótimo feedback ao professor sobre a aquisição de conhecimentos do tema trabalhado em sala, como também permite ao mesmo catalogar as possíveis dúvidas ainda existentes nos alunos sobre o assunto discutido em sala. 
De acordo com Anastasiou e Alves (2004), a objetividade é bastante estimulada nessa estratégia pela sua forma de organização que toma por base o número 6 (seis): 6 (seis) participantes, 6 (seis) minutos para discussão e 6 (seis)minutos para a socialização. Como o tempo é distribuído entre os grupos, o professor e os próprios estudantes conseguem formular uma visão global dos avanços e dificuldades da classe. Aspectos atitudinais são sempre objeto de avaliação nas atividades grupais e podem ser estimulados e implementados gradativamente ao longo do trabalho escolar.

Da teoria à prática: vivenciando o fazer docente a partir da inserção das estratégias de ensino em uma sala de aula

Este relato de experiência discorre sobre a utilização de duas estratégias de ensino aplicadas em uma turma de 36 servidores municipais que participaram do curso de capacitação sobre ética no serviço público, ofertado pela Escola de Governo no município de São Francisco do Conde, no Estado da Bahia. O curso teve duração de 24 horas e foi desenvolvido no período de 6 a 13 março de 2018. Para o desenvolvimento do curso foram utilizadas as seguintes estratégias de ensino: aula expositiva dialogada e Phillips 66. Estas estratégias foram escolhidas, levando-se em consideração o tempo para a realização do trabalho, o público-alvo, as estruturas disponíveis e os objetivos que pretendíamos alcançar.

Nesse sentido, o trabalho foi planejado e desenvolvido em três momentos. No primeiro, momento tínhamos como objetivo promover uma integração da turma. A ideia foi criar um ambiente de entrosamento e descontração e, para isso, utilizamos a dinâmica de grupo conhecida pelo nome de "quebra-gelo" ou "apresentação". No decorrer de boa parte do curso, adotamos a estratégia da aula expositiva dialogada e, na parte final do curso, adotamos a estratégia de ensino Philips 66 para fazermos uma síntese do que foi discutido em todo o curso, bem como percebermos as lacunas na abordagem do tema.

Tudo começou quando convidamos os alunos para reorganizar a sala de aula, formando um grande círculo com as cadeiras. Em seguida, pedimos aos mesmos que permanecessem de pé e solicitamos a cada um deles que se apresentassem, revelando o nome, idade, setor de trabalho, função que ocupada dentro da estrutura administrativa da Prefeitura, motivo que o 
levou a escolher um curso como o nosso e o que eles mais gostavam de fazer no tempo vago ou no lazer. Não foi estipulado um tempo limite para a apresentação, uma vez que a nossa intenção era permitir que todos se sentissem à vontade para interagirem na dinâmica.

Após a apresentação com a dinâmica de grupo verificamos que muitos já se conheciam e mantinham relação de amizade desde o tempo da infância; alguns eram vizinhos de bairro. Tivemos situações em que as pessoas trabalhavam na mesma instituição, em setores diferentes, mas não se conheciam, ainda que a cidade seja pequena com cerca de 36.000 habitantes. A dinâmica nos serviu para realizarmos um breve diagnóstico do perfil da turma e vale ressaltar que esta foi de grande valia para se criar um ambiente propício ao desenvolvimento da empatia e do entrosamento entre todos nós.

Ao finalizarmos a dinâmica apresentamos o plano de aula e a metodologia que seria utilizada. Nesse momento, uma série de acordos foram firmados entre todos nós, como, por exemplo, que a aula poderia ser interrompida a qualquer momento para perguntas referentes ao tema abordado; que os alunos deveriam se comprometer em colaborar com as discussões, fazendo intervenções a partir de suas experiências, uma vez que a estratégia escolhida foi a aula expositiva dialogada.

A aula foi planejada de modo a produzir o livre debate, já que a nossa intenção foi associar o conteúdo teórico com as experiências dos alunos, trazendo para dentro das discussões situações corriqueiras do seu cotidiano numa perspectiva crítica.

Como forma de ilustrar o conteúdo abordado utilizamos textos on-line "o jeitinho brasileiro", referências audiovisuais, entrevistas com o professor Mario Sérgio Cortela, filósofo brasileiro, que trata sobre diferentes temas contemporâneos como a ética e a vergonha na cara, bem como matérias de telejornais que abordam sobre o tema da ética na administração pública.

Iniciamos a aula expositiva dialogada, pedindo aos alunos para darem uma definição de ética, partindo da seguinte pergunta: O que é ética para vocês? Muitos conceitos apareceram, tais como: "ética é não pegar nada dos outros"; "ética é chegar no horário no trabalho"; "ética está relacionada as escolhas que as pessoas fazem na vida"; outros associaram a ética a "prática do bem e do mal". Ainda houve um conceito de ética atrelado, digamos assim, a uma concepção metafísica da existência humana como "ética é seguir as vontades de Deus". Esses 
foram alguns dos vários conceitos de ética apresentados pelos alunos, numa espécie de tempestade de ideias. A partir deles, buscamos associar as percepções diversas sobre ética ao arcabouço epistemológico desenvolvido pela filosofia sobre o tema, calçando as nossas abordagens sobre as concepções de Platão e Sócrates.

Em seguida, abrimos para o debate com os seguintes questionamentos: Vocês se consideram pessoas éticas? Pode uma pessoa ser ética e antiética ao mesmo tempo?

Os questionamentos apresentados se propuseram a provocar uma reflexão e ao mesmo tempo incitar a criticidade dos alunos para que eles pudessem fazer as conexões com sua realidade e seu contexto.

O resultado foi bastante interessante, visto que a maioria da turma participou ativamente das discussões, sendo perceptível o entrosamento no grupo. Vale destacar que o mais interessante dessa prática foi perceber a vontade deles em compartilhar as suas experiências, querendo saber se poderiam ou não ser considerados pessoas éticas ou antiéticas. Outra situação bem interessante foi quando trabalhamos com alguns dos conteúdos do código de ética dos servidores públicos municipais, sobretudo as seções que tratam dos direitos e deveres. Assim, solicitamos aos alunos que descrevessem uma conduta praticada por eles considerada indevida. O curioso foi que muitos alunos relataram que sequer conheciam a existência de um código que regia, eticamente, o seu fazer enquanto servidores públicos. O próprio desconhecimento de um documento como esse impossibilitava que o servidor promovesse uma reflexão mais crítica sobre os seus hábitos cotidianos, como, por exemplo, a forma de tratamento aos usuários do serviço público com uma linguagem informal, utilizandose de gírias para denominar pessoas como: "diga aí, B", quando deveriam tratar esses usuários por "senhor ou senhora".

Outra prática bastante relatada por eles era o fato de não compensarem efetivamente os horários de ponto facultativo dado pela prefeitura nos dias que antecediam os feriados. Outra conduta não ética muito citada pelos alunos foi o fato dos mesmos deixarem de fazer os seus deveres funcionais para ficarem à disposição de seus chefes para trabalhos particulares.

Quando trabalhamos com o texto "jeitinho brasileiro" as discussões foram bastante calorosas na medida em que, para muitos alunos, o "jeitinho brasileiro" já faz parte da nossa própria cultura e não temos mais o que fazer diante desta situação, já que os políticos, que 
deveriam dar exemplos, são os primeiros a praticá-lo para levar vantagem em tudo. Já outra parte da turma, considerou o "jeitinho brasileiro" um problema sério para o país, que extrapola o serviço público, uma vez que vários outros exemplos de condutas não éticas foram citados e o mais corriqueiro esteve relacionado ao fato de não se respeitar o sinal de trânsito.

Por fim, encerramos o curso com a aplicação da estratégia de ensino Philips 66. Dividimos a turma em 5 grupos com 6 membros. Explicamos como seria a atividade e em seguida passamos um vídeo do filósofo Mário Sérgio Cortela sobre a ética e pedimos para os grupos discutirem sobre a diferença entre ética e moral, vícios e virtudes.

Observamos que durante a realização da atividade os cursistas discutiram não somente as ideias apresentadas no vídeo disponibilizado, mas também conseguiram resgatar muitos dos conteúdos trabalhados durante todo o curso. Conseguiram realizar análises críticas de suas práticas profissionais; admitiram que precisavam abandonar velhos hábitos para se tornarem pessoas virtuosas; refletiram sobre a necessidade de conhecerem as normas e legislações que regulamentam as suas condutas éticas como servidores públicos. Todavia o mais interessante, digamos assim, de todas essas manifestações, foi o fato dos alunos perceberam que a ética não está restrita apenas à execução dos seus serviços dentro da estrutura administrativa da Prefeitura, mas também está imbricada em toda as suas vidas. Pensar em ética, a partir do curso, passou a ser pensar o eu a partir do outro, isto é, pensar no meu bem-estar sem me despreocupar com o bem-estar do outro. Assim, podemos crê que diante dos momentos críticos atravessados pelo nosso país, pensar eticamente seria uma grande possibilidade para construirmos uma nação mais sustentável ao longo do tempo.

\section{Considerações finais}

Neste relato foi possível descrever uma experiência vivenciada em sala de aula a partir de um processo de ensinagem, utilizando duas estratégias de ensino em um curso de formação de servidores. No planejamento do curso, várias variáveis foram consideradas para que pudéssemos alcançar o nosso objetivo. Um dos fatores mais relevante foi o quantitativo de participantes, o tempo disponível e a estrutura física existente, já que se tratava de um curso direcionado para a formação de profissionais que trabalham como assistente de classe nas 
escolas de ensino fundamental. Nosso propósito foi criar um ambiente em que a maioria se sentisse provocado a participar sem receio da exposição individual, refletindo sobre o tema, opinado a partir do seu lugar e de suas experiências, interagindo com os colegas, compartilhando situações do cotidiano e trabalhando em grupo.

Ressaltamos que, tanto na etapa de elaboração e planejamento do curso como em sua execução tivemos a preocupação com a aplicação estrita das estratégias escolhidas. Como essa foi a primeira vez que a utilizamos, a sensação de medo, incerteza e insegurança nos assustou, assim como é assustador a experiência do novo, porém necessário para se romper com os modelos e os padrões que não inserem os sujeitos como protagonistas de suas formações.

É necessário registrar também que não existe planejamento perfeito em sala de aula, pois estamos nos relacionando com o sistema vivo, dinâmico e complexo, que exige do professor flexibilidade, capacidade de lidar com o inesperado, ser autoridade sem exercer autoritarismos, capacidade de mediar conflitos, valorizando e encorajando a opinião e o pensamento dos alunos. O professor, como diria o grande filósofo iluminista Montaigne, pode até não concordar com a opinião do seu aluno, mas deve defender o direito dele dizê-la até o final.

A nossa análise em relação ao uso da estratégia da aula expositiva dialogada é que não é uma estratégia simples e fácil de ser aplicada. Na verdade, é uma estratégia que demanda tempo para aplicá-la e talvez seja mais apropriada para disciplinas com carga horária de 40 ou 60 horas, pois fica difícil ter que dar conta do conteúdo da aula propriamente dita e dar conta ao mesmo tempo das intervenções dos alunos. Já a estratégia de ensino da Phillips 66 é muito eficiente para trabalhos em grupos, uma vez que, como já dito, permite fazermos sínteses sobre os assuntos tratados numa aula, bem como percebermos possíveis lacunas no processo de ensino e aprendizado dos alunos.

À guisa de conclusão, esperamos que novas pesquisas possam ser realizadas no sentido de dar continuidade às investigações que se proponham a relatar as experiências de aplicação das estratégias de ensino em diferentes contextos educacionais, de modo a se revelar as suas potencialidades e as suas limitações, alimentando ou realimentando a literatura teórica sobre o tema. 


\section{Referências}

ANASTASIOU, L. G. C.; ALVES, L. P. Estratégias de ensinagem. In: ANASTASIOU, L. G. C.; ALVES, L. P. Processos de ensinagem na universidade:pressupostos para as estratégias de trabalho em aula, Joinville: UNIVILLE, 2004. p.67-100.

ANASTASIOU, L. G. C.; ALVES, L. P. (orgs.). Estratégias de ensinagem. In: ANASTASIOU, L. G. C.; ALVES, L. P. Processos de ensinagem na universidade: pressupostos para as estratégias de trabalho em aula. 8. ed. Joinville: UNIVILLE, 2009, p. 68-100.

BAUMAN, Z. Modernidade líquida. Trad. Plínio Dentzien. Rio de Janeiro: Jorge Zahar, 2002.

MORAN, J. M. Ensino e aprendizagem inovadores com tecnologias audiovisuais e telemáticas. In: MORAN, J. M.; MASETTO, M. T.; BEHRENS, M. A. Novas tecnologias e mediação pedagógica. 19. ed. São Paulo: Papirus, 2012. p.11-65.

Recebido em janeiro 2020.

Aprovado em março 2021. 